\title{
Hierarchical and Droop Method for DC Micro-grid Bus Voltage under Isolated operation
}

\author{
Xiangyang Yan ${ }^{1}$, Ningkang Zheng ${ }^{1}$, Yilong Kang ${ }^{1}$, Huanruo $\mathrm{Qi}^{1}$, Kai $\mathrm{Li}^{1}$, Haowei Pei ${ }^{1}$, Kai Niu ${ }^{1}$ \\ ${ }^{1}$ State Grid Henan Economic Research Institute, Zhengzhou, Henan, 450000, China
}

\begin{abstract}
Nowadays, distributed generation technology is of great help to the efficient utilization of new energy. If the distributed power supply is connected to the DC micro-grid, it will be more secure and reliable. Therefore, it is necessary to control the voltage stability of the DC bus and ensure the balance of the source charge power of system to ensure the power supply quality and safety of the DC micro-grid. There are two operation modes of DC micro-grid: connected operation and isolated operation, and isolated operation control is the foundation and key of system-level control of DC micro-grid. To solve the problem of bus voltage fluctuation in isolated dc micro-grid, this study proposes a voltage hierarchical-droop control strategy for DC micro-grid, which can effectively improve the stability of the DC bus voltage. Last, this study builds the simulation model of DC micro-grid in the MATLAB/Simulink platform to verify the validity and feasibility of the proposed control strategy.
\end{abstract}

\section{Introduction}

With the accelerating pace of economic globalization, the energy situation the human society faces is becoming more and more severe. Due to the increasing demand for energy in various countries, more attention is paid to the development of renewable energy [1-2]. At the same time, in the academic circle, the distributed generation technology based on renewable energy and micro-grid composed of distributed generation have become the focus of scholars at home and abroad [3-5]. There are two kinds of micro-grids: DC micro-grid and $\mathrm{AC}$ micro-grid. Compared with AC, DC has the advantages in terms of simple conversion device and low cost. Moreover, we don't need to consider the reactive power and frequency problems in DC micro-grid, as well as the harmonic influence and a series of problems caused by three-phase imbalance when supplying power to a load, so quality of its power supply is higher. However, there are still many problems to be solved. Similar to the AC micro-grid, the DC also contains a large number of power electronic devices. When the load fluctuation or the output fluctuation of distributed power supply occurs, the line voltage will change dramatically, which will endanger the safe and stable operation of the system.

It is well known that DC micro-grid generally has low capacity, such as the supply of distributed power and the change of DC load. Once these changes are disturbed, power imbalance will appear in the system, which will lead to the voltage fluctuation of DC bus. Therefore, it is very necessary to adopt appropriate control strategy to realize the balance of power and the stability of DC bus voltage. As for the stability of power and voltage of DC distribution network, a new master-slave converter station is proposed in literature [6], which is respectively regarded as the switch control method of the balance point of system power and power realization. In literature [7], a decentralized discrete time adaptive neural network control method is proposed for DC distribution networks under interconnection. In addition, literature [8] put forward a distributed adaptive droop control method in DC distribution network, so as to realize the plug-and-plug of distributed power supply.

In order to solve the problem that the voltage of DC bus tends to fluctuate, this study takes typical isolated DC micro-grid as the object and proposes a hierarchical-droop control strategy of DC micro-grid voltage. Finally, this study verifies the effectiveness and feasibility of the proposed control strategy through MATLAB/Simulink simulation.

\section{The Structure of DC Micro-grid}

As shown in Figure 1, a typical DC micro-grid topology consists of distributed power supply, energy storage device, DC load and related power electronics devices. Because the distributed power supply and flexible load in the DC micro-grid are highly volatile, and the DC micro-grid, which contains many power electronics components, does not have the high inertia of conventional units. Therefore, when the power fluctuates, the bus voltage of the DC micro-grid system is greatly affected.

*Corresponding author's e-mail: 245747911@qq.com 


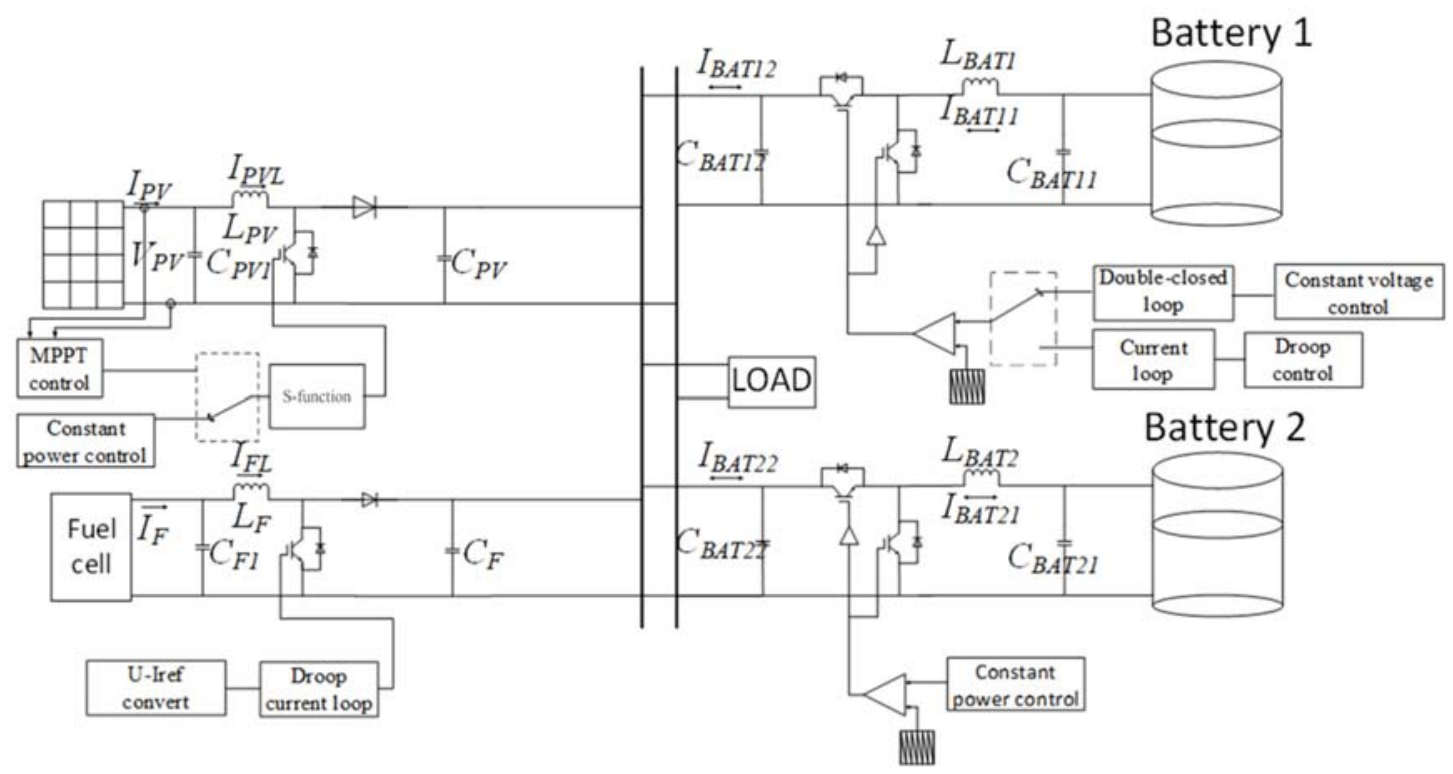

Figure 1. Topology of DC Micro-grid

As shown in Figure 2.1, we suppose that $P_{\text {pvo }}$ is the output power of photovoltaic cells, $P_{\text {bato }}$ is the outlet power of energy storage, $P_{\mathrm{L}}$ is the DC load consumption power, and $P_{\text {bus }}$ is the charging power of the bus side capacitor, finally the power relationship is

$$
P_{\text {pvo }}=P_{\text {bato }}+P_{L}+P_{b u s}
$$

The change of Dc bus voltage will cause the DC side capacitance charging and discharging. We assume that after a period of time $T$, the DC bus voltage changes from the rated voltage $U_{\mathrm{dc}}^{*}$ to the actual voltage value $U_{\mathrm{dc}}$, and the energy of the DC side capacitance changes to $\Delta E_{\mathrm{dc}}$, then

$$
\Delta E_{\mathrm{dc}}=T P_{\text {bus }}=\frac{1}{2} C_{\mathrm{dc}}\left(U_{\mathrm{dc}}^{* 2}-U_{\mathrm{dc}}^{2}\right)
$$

Combined with formula (1) and formula (2), it can be obtained

$$
U_{\mathrm{dc}}=\sqrt{U_{\mathrm{dc}}^{* 2}-\frac{2 T}{C_{\mathrm{dc}}}\left(P_{\mathrm{pvo}}-P_{\mathrm{L}}\right)+\frac{2 T}{C_{\mathrm{dc}}} P_{\text {bato }}}
$$

It can be seen from the formula (3) that the change of distributed photovoltaic (PV) power output and of load consumption power can cause DC bus voltage fluctuation. At this point, the input and output power of the energy storage unit must be properly adjusted to ensure the stability of bus voltage, and at the same time make the power balance of the DC micro-grid system, and finally realize the stability of DC bus voltage.

\section{The Conventional Droop Control}

This part is droop control, which is a common control strategy of DC micro-grid DC/DC converter. Its working principle is to control the converter by using the linear relationship between the output power and the terminal voltage. It uses the principle of a linear relationship between the output power of a distributed power supply and the terminal voltage. Its control equation is as follows

$$
U_{\mathrm{dc}}=U_{\mathrm{d}}^{*}-k P_{\mathrm{d}}
$$

In the formula, DC bus voltage is $U_{\mathrm{dc}}$; the rated value of the output voltage of the distributed power supply is $U_{\mathrm{d}}^{*}$; the droop coefficient is $k$; the output power of distributed power supply is $P_{\mathrm{d}}$. Then, Figure 2.1 shows the droop control curve of DC bus voltage $U_{\mathrm{dc}}$ and output power $P_{\mathrm{d}}$. We can see that the insufficient active power will lead to the decrease of DC bus voltage when the active load of the system suddenly increases, on the contrary, the DC bus voltage will increase.

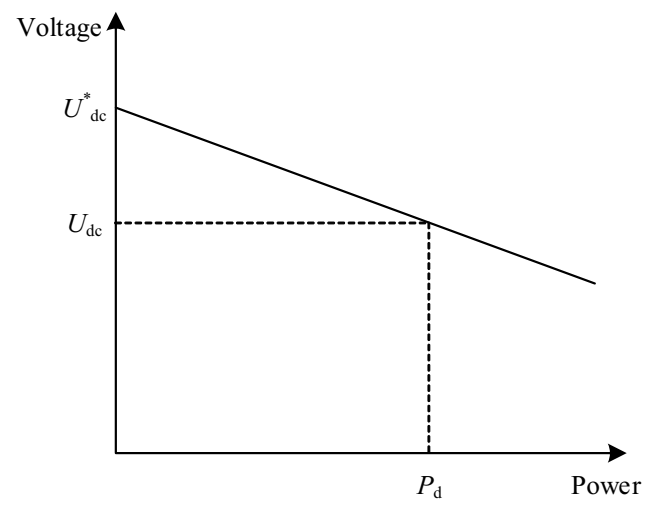

Figure 2. Droop control curve of DC/DC converter

The droop control block diagram of DC/DC converter for DC micro-grid is shown in Figure 2. It can be seen that the voltage on the load side is $U$; the DC power side 
current is $I_{1}$. As can be seen from the figure, we first calculated the output power $P_{\mathrm{d}}$ by taking the voltage $U$ and current $I$ at the load side, and then calculated the reference voltage according to the droop curve in formula (4). Then we get PWM modulation signal through voltage and current double loop PI control, and finally control the converter switching tube.

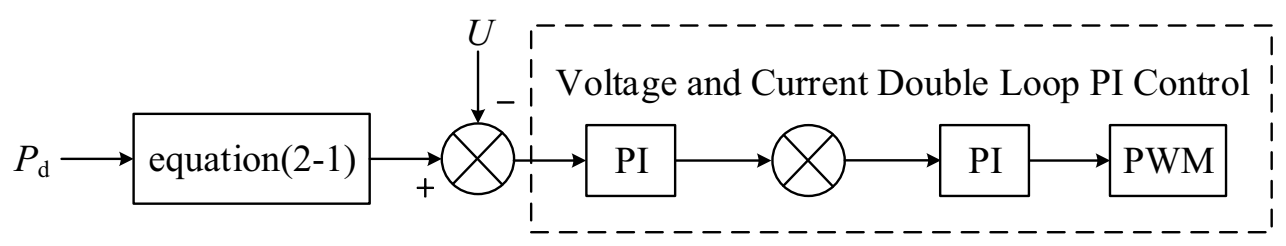

Figure 3. Droop control block diagram of DC/DC converter

As we all know, in practical application, the conventional droop control strategy has defects such as long transient response time and large output voltage deviation. This results in the failure to provide stable DC bus voltages for the DC micro-grid.

\section{The Hierarchical-Droop Control of Bus Voltage}

Firstly, the adoption of droop control strategy needs to ensure a smaller voltage deviation as far as possible, and then coordinate the output power of distributed power supply and load power according to the proportional relation of droop coefficient, so as to achieve the power balance within the DC micro-grid system [5-9].The principle of bus voltage hierarchical-droop control is that the switching threshold of each distributed power supply is first divided into different voltage segments. Then, the voltage drop characteristics of each distributed power supply are used to determine the respective operation mode, so as to ensure the power balance of the DC micro-grid. .In essence, the bus voltage hierarchical-droop control is also the control refers to the control of each distributed power supply and energy storage unit $\mathrm{DC} / \mathrm{DC}$ converter in the DC micro-grid. Generally speaking, when outputting power to DC micro-grid, the distributed power supply has three working modes: constant power output, droop characteristic output and off. The initial value of each working mode is the switching threshold of the distributed power supply. In other words, when the voltage of dc bus is greater than the switching threshold, the working mode is off mode. When DC bus voltage is less than the switching threshold, the working mode is the output state of droop characteristic. In addition, when the system continues to increase the access load, and the required power is greater than the maximum output power of the distributed power supply, the distributed power supply mode will be changed to the constant power output mode.

Then this study takes distributed power supply in constant power output mode as an example to analyze the specific operation mechanism of bus voltage hierarchical-droop control. As shown in Figure 4, the DC micro-grid includes distributed power supply 1, 2 and DC load. .In addition, there are two voltage droop regions in this example. In other words, distributed power supply 1 can only output power to the system in voltage segment 1 , but in voltage segment 2 , distributed power supply 1 and distributed power supply 1 can input power to the system simultaneously. Among them, when the bus voltage is $\mathrm{V}_{1}$, distributed power supply 1 is connected to the system; when the bus voltage is $V_{2}$, distributed power supply 2 is connected to the system.

It can be seen from Figure 3.2 that when the DC load power is $P_{\mathrm{L} 1}$, the needs of the system can be meet by the output power of distributed power supply 1. Therefore, the DC bus voltage falls within the range of voltage segment 1 .At this point, the distributed power supply 1 is running in droop output mode, while distributed power supply 2 is not connected. When the load power is $P_{\mathrm{S} 1}$, the load power is equal to the maximum output power of distributed power supply 1 . In this case, the distributed power supply 1 is working in the constant power output mode, while the distributed power supply 2 is still not working then the voltage value of $\mathrm{DC}$ bus is $\mathrm{V}_{2}$; When the load power to $P_{L 2}$, which has been more than a distributed power supply 1 that provides maximum power, and the distributed power supply 1 is still working at this time in constant power output mode, DC bus voltage drops to less than $V_{2}$ a certain value. At the point, the voltage segment 2 is entered, and the distributed power supply 2 is put into operation and works in the droop output mode. 


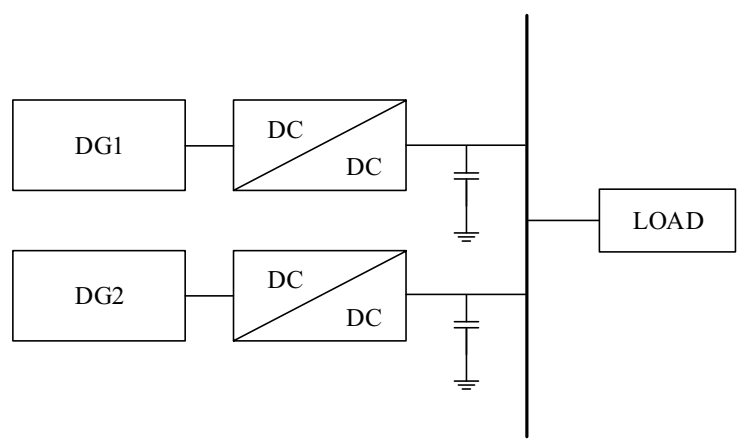

Figure 4. Power-injected DC Microgrid

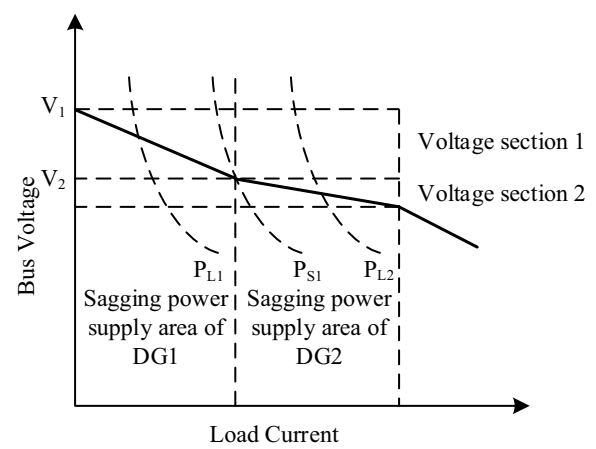

Figure 5. Bus Voltage Droop Curve of Power-injected DC Microgrid

The setting of reference voltage is one of the most important steps in bus voltage hierarchical-droop control. The sequence is from the high priority distributed power supply to the low priority distributed power supply. Generally speaking, the rated voltage of DC micro-grid is the power supply voltage with the highest priority, followed by the distributed power supply reference voltage with the next highest priority, as shown in Formula (5).

$$
U_{r e f(\mathrm{n})}=U_{r e f(\mathrm{n}-1)}-U_{(\mathrm{n}-1)}-U_{e}
$$

threshold with priority level $n ; U_{r e f(\mathrm{n}-1)}$ is the power voltage threshold with priority level $n-1 ; U_{(n-1)}$ represents the voltage drop caused by the impedance of the two lines; $U_{e}$ represents the sum of bus voltage fluctuation and correlation error.

In order to achieve the optimal state of performance and economic benefits, this study regards the distributed photovoltaic power generation as the highest level of system energy optimization in DC micro-grid, and is always output at the maximum power within the range of voltage fluctuation. .At the same time, the maximum power is always output within the range of voltage fluctuation. In addition, as the energy buffer unit in the DC micro-grid,the energy storage unit plays the role of "Peak and Filling". Furthermore, when the load power in the system is small or the light intensity is high, the energy storage unit in the charging state can suppress the rise of dc bus voltage. When the load power in the system is large or the light intensity is low, the energy storage unit works in the discharge state to suppress the drop of the bus voltage. Therefore, $t$ we regard the energy storage unit as the second level of system energy optimization. The fuel cell is used as the backup power source of the DC micro-grid system and is put into the system when the system energy is insufficient. which is put into the system when the system energy is insufficient. Finally, we take the fuel cell as the third stage of the system energy optimization.

Figure 6 shows the schematic diagram of hierarchical-droop control of DC micro-grid bus voltage. In the figure, we can see that when the load power changes, the DC bus voltage changes accordingly. When the DC bus voltage changes, the mode of the DC micro-grid is converted. This diagram shows the process of realizing system energy management by bus voltage drop.

In the formula, $U_{r e f(n)}$ is the power supply voltage

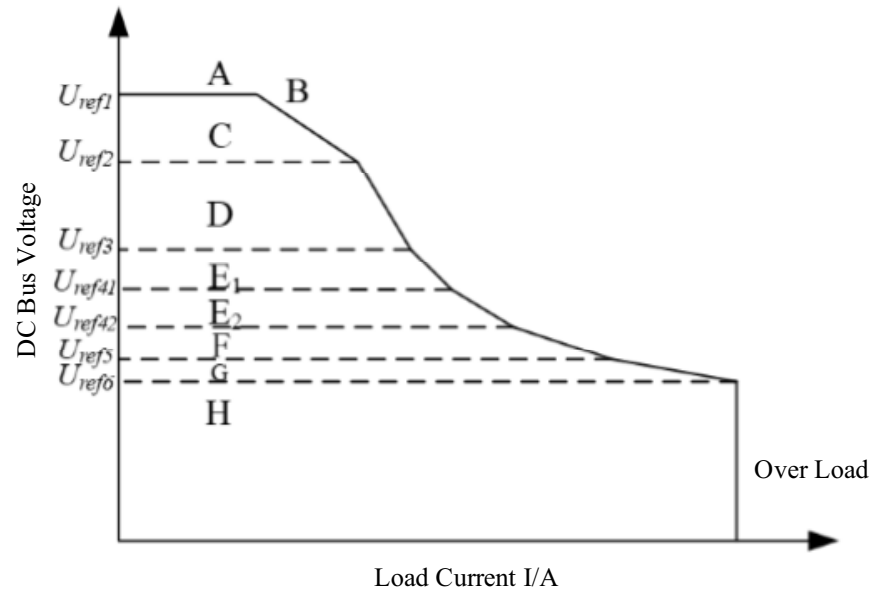

Figure 6. Droop Curve of Bus Voltage of DC Micro-grid 


\section{The Simulation Analysis}

In order to verify the effectiveness and feasibility of the proposed control strategy, this study builds a DC micro-grid simulation model as shown in Figure 1 on the MATLAB/Simulink platform, and the simulation parameters of the whole system were shown in Table 1.

Table 1. Simulation Model Parameters of System

\begin{tabular}{cc}
\hline System Parameters & Value \\
\hline Bus rated voltage & $380 \mathrm{~V}$
\end{tabular}

PV maximum output power

$5000 \mathrm{~W}$

Energy storage terminal voltage

$190 \mathrm{~V}$

Maximum output power of energy storage

Maximum output power of fuel cell

The simulation gives various conditions of changes of light intensity and bus voltage under consideration of various working conditions, as shown in Figure 7.

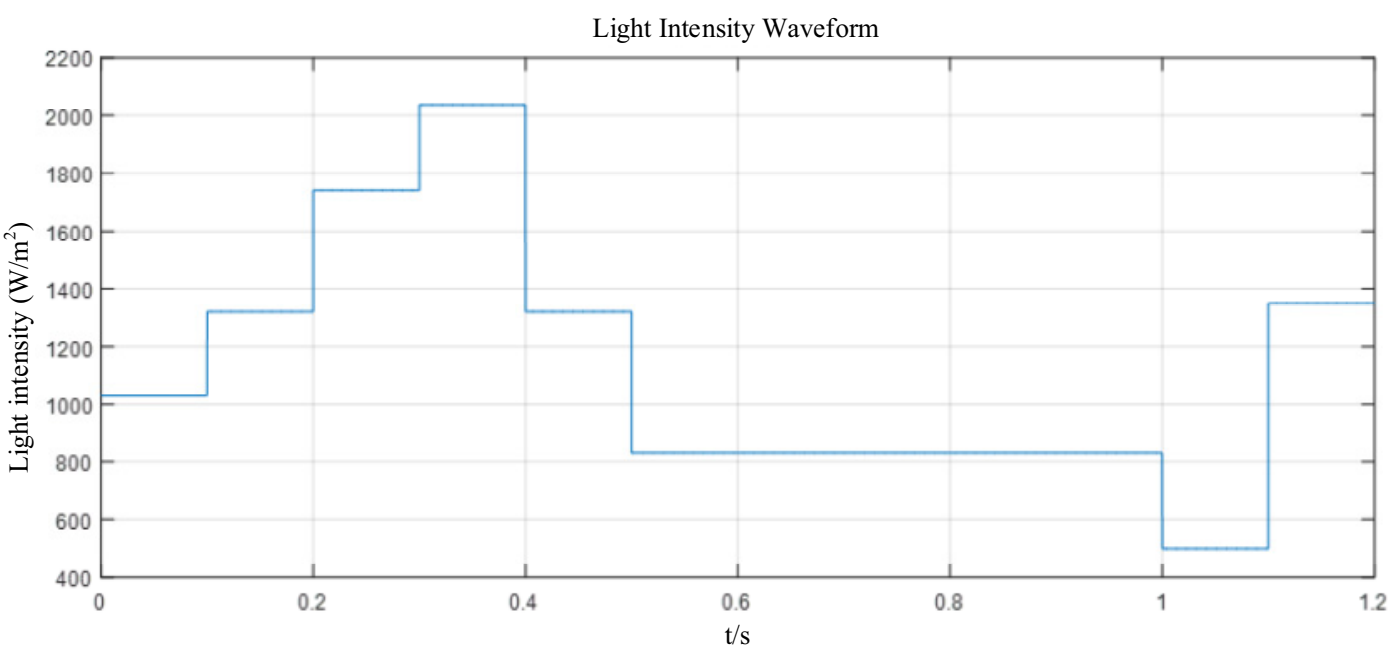

Figure 7. Change Curve of Light Intensity

Figure 7 shows the simulation results of DC bus voltage. Take $0 \sim 0.6 \mathrm{~s}$ as an example to illustrate the change of DC bus voltage and system operation state caused by illumination change.

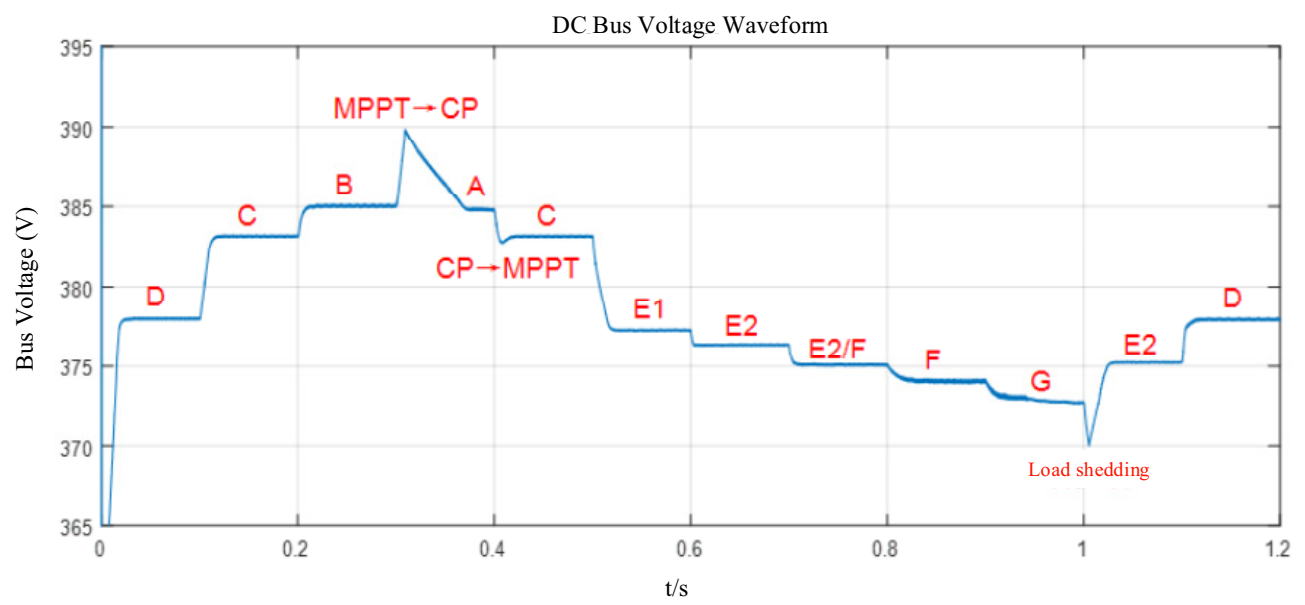

Figure 8. Change Curve of Bus Voltage

It can be seen from Figure 8 that when $0<\mathrm{t}<0.1 \mathrm{~s}$, the output power of distributed photovoltaic is equal to the load power. At this time, distributed photovoltaic is in MPPT mode, battery and fuel cell do not work, DC bus voltage is maintained at $378 \mathrm{~V}$, and the system works in state D.

When $0.1 \mathrm{~s}<\mathrm{t}<0.2 \mathrm{~s}$, with the increase of light intensity,, the output power of distributed photovoltaic
(PV) is greater than the load power, DC bus voltage up to $383 \mathrm{~V}$, energy storage unit access system and is in droop mode, absorbing the excess electricity. At this time, distributed photovoltaic still work in MPPT mode, fuel cell does not work, and the system working state in $\mathrm{C}$;

When $0.2 \mathrm{~s}<\mathrm{t}<0.3 \mathrm{~s}$, with the further increase of light intensity, distributed photovoltaic (PV) and load power further, DC bus voltage up to $385 \mathrm{~V}$, the unit of 
energy storage from the droop charging operation mode into a current-limiting charging mode. At this time, distributed photovoltaic (PV) is still running in MPPT mode, fuel cell does not work, and the system working in state $\mathrm{B}$;

When $0.3 \mathrm{~s}<\mathrm{t}<0.4 \mathrm{~s}$, the light intensity increases further, The difference between distributed photovoltaic (PV) power output and load power is greater than the maximum absorption power of the energy storage unit, thus the DC bus voltage continues to rise; when the DC bus voltage up to $390 \mathrm{~V}$, the system judges power overflow and changes the working mode of distributed photovoltaic from MPPT mode to power limited mode, when the output power of distributed photovoltaic (PV) decreases to ensure that the energy storage unit can absorb the difference between the output power of distributed photovoltaic and the load power, in the meanwhile, the DC bus voltage drops to $384 \mathrm{~V}$, the energy storage unit works in droop charging mode, and the fuel cell does not work, thus the overall system is working in state $\mathrm{A}$

When $0.4 \mathrm{~s}<\mathrm{t}<0.5 \mathrm{~s}$, the light intensity decreased greatly, the energy storage unit can absorb the difference between the maximum output power of the photovoltaic system and the power of the load, therefore, distributed photovoltaic (PV) is transformed from a limited power output mode to an MPPT output mode. At this time, the system state is the same as that at $0.1 \mathrm{~s}<\mathrm{t}<0.2 \mathrm{~s}$, the energy storage unit running on droop charging mode, fuel cells are still not access, DC bus voltage maintains at 383 $\mathrm{V}$, and the overall system is in state $\mathrm{C}$;

When $0.5 \mathrm{~s}<\mathrm{t}<0.6 \mathrm{~s}$, with the light intensity drops further, distributed photovoltaic maximum power output is less than the load power, DC bus voltage drop to about $377.5 \mathrm{~V}$, thus the energy storage unit is converted from droop charging mode to droop discharging mode to output the power shortage of the system. In this case, the fuel cell is not connected to the system, and the system generally works in state E1.

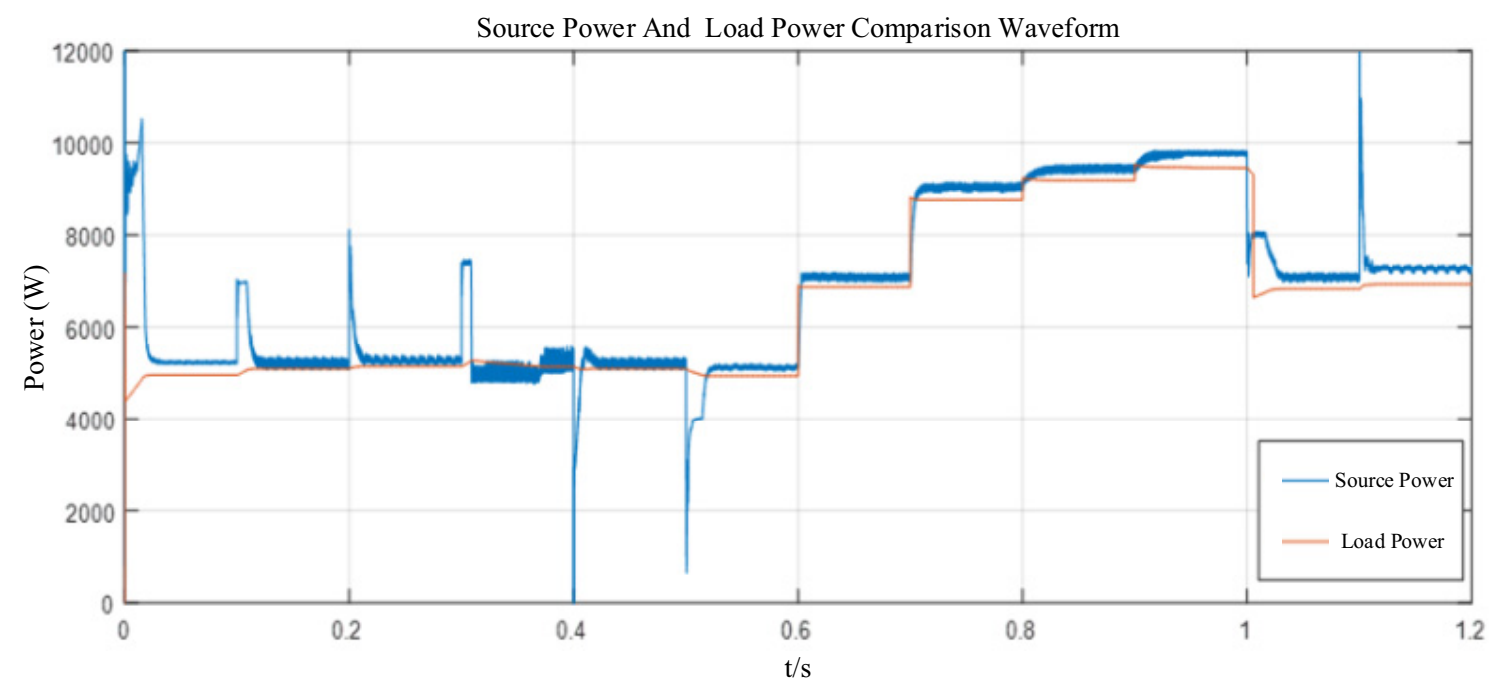

Figure 9. Comparison Curve of Source-charge Power

Figure 9 shows the comparison waveform of the source-charge power of the DC micro-grid system. It can be seen from the figure that within $0<\mathrm{t}<1.2 \mathrm{~s}$, the source charge power of the system is basically balanced. As can be seen from the curve of DC bus voltage, the system of bus voltage is between $370 \mathrm{~V}$ and $390 \mathrm{~V}$ stably, meeting the control requirements.

\section{Conclusions}

To solve the problem of isolated operation of DC micro-grid bus voltage fluctuation, this study puts forward a kind of bus voltage hierarchical-droop control strategy. .In this study, the proposed control strategy can coordinate the control of energy. And this control method does not need to establish the communication between distributed power sources, nor the regulation of the central control unit. It only needs to establish the local control to achieve the power balance of the system, stabilize the DC bus voltage, and greatly improve the stability and reliability of the system. In addition, a simulation model of DC micro-grid with the proposed control strategy was established on the MATLAB/Simulink platform, and the whole system was simulated. .The simulation results show that the DC bus voltage of the system can be stable and meet the control requirements. The results also show that the proposed control strategy has good dynamic performance.

\section{References}

1. XIE H, ZHENG S, NI M, et al. Microgrid development in China: a method for renewable energy and energy storage capacity configuration in a megawatt-level isolated microgrid[J]. IEEE Electrification Magazine, 2017, 5(2): 28-35.

2. SPB Publishing, The Hague.PENG Ke, ZHANG Cong, XU Bingyin, et al. Status and prospect of pilot projects of integrated energy system with 
multi-energy collaboration[J]. Electric Power Automation Equipment, 2017, 37(6): 3-10.

3. TANG Min'an, GAO Xiaohong. Grid-connected control of microgrid with photovoltaic and energy storage systems under unbalanced grid voltage conditions[J]. High Voltage Engineering, 2019, 45(6): 1879-1888.

4. HAJIMIRAGHA A, ZADEH M R, MOAZENI S. Microgrids frequency control considerations within the framework of the optimal generation Scheduling problem[J]. IEEE Transactions on Smart Grid, 2015, 6(2): 534-547.

5. ZHANG Songjie, QIN Wenping, REN Chunguang, et al. Control strategy for hybrid energy storage system in bipolar-type DC microgrid[J]. High Voltage Engineering, 2018, 44(8): 2761-2768.

6. ZHENG G, LI Y, LIU H, et.al. Research on Distributed Photovoltaic Grid-connected Power Control Strategy of Direct Current Distribution Network[J]. Power Electronics, 2019, 53(12): 71-73.

7. KAZEMLOU S, MEHRAEEN S. Decentralized discrete-time adaptive neural network control of interconnected DC distribution system[J]. IEEE Transactions on Smart Grid, 2014, 5(5): 2496-2507.

8. NASIRIAN $\mathrm{V}$, DAVOUDI A, LEWIS L. Decentralized adaptive droop control for DC distribution systems[J]. IEEE Transactions on Energy Conversion, 2014, 29(4): 944-956. 